\title{
Potential Multi-Function Cylinder as Wave Attenuator.
}

\author{
Nor Aslinda Awang ${ }^{1}$ Norzana Mohd Anuar ${ }^{1,2^{*}}$ and Faridah Jaffar Sidek ${ }^{3}$ \\ ${ }^{1}$ Coastal and Oceanography Research Centre, National Hydraulic Research Institute of Malaysia, Selangor, Malaysia \\ ${ }^{2}$ Civil and Environmental Engineering Department, Universiti Teknologi Petronas, Perak, Malaysia \\ ${ }^{3}$ Coastal and Offshore Engineering Institute, Universiti Teknologi Malaysia, Kuala Lumpur, Malaysia
}

*Corresponding author: Norzana MA, Coastal and Oceanography Research Centre, National Hydraulic Research Institute of Malaysia, Selangor, Malaysia, Tel: +603.89476489; E-mail: norzana@nahrim.gov.my

Received Date: July 13, 2018;Accepted Date: August 17, 2018; Published Date: August 24, 2018

Copyright: (c) 2018 Nor Aslinda A, et al. This is an open-access article distributed under the terms of the Creative Commons Attribution License, which permits unrestricted use, distribution, and reproduction in any medium, provided the original author and source are credited.

\begin{abstract}
An experimental investigation, conducted in unidirectional waves with different wave conditions and model configurations were conducted to assess the wave energy loss on cylinder obstacles. This study presents a significant finding on porous cylindrical model. The basic concept of porous cylinder breakwater is to serve as a pervious barrier where particle movements are more which is more environmental friendly and allow the passage of tidal currents with least disturbance where littoral drift is predominant. For the study, Two sizes of cylinder were used, $100 \mathrm{~mm}$ and $200 \mathrm{~mm}$ with four different porosities ranging from 0.0625 to 0.48 respectively. The influences of water level, wave steepness, wave number and porosities were studied. The test results shown that when the percentage of porosity decreased, more wave energy was dissipated, this resulted in the decrease in transmitted wave heights. Furthermore, it was also found that lower water level has a significant influence on the loss coefficient at bigger model size with El being more than 0.60 at a water level $0.27 \mathrm{~m}$ compared to El being less than 0.40 at water level $0.35 \mathrm{~m}$ for similar porosity. Overall, the bigger model (single or double cylinder) with lower porosity $(P=6.25 \%$ and $14 \%)$ showed promising performance in reducing wave height at the lee of the model, having high percentage of wave energy loss, and smaller model has been found to be the least effective wave attenuator model to the same environments among all three models. In a way, cylindrical structure being porous could potentially be used together or alone as a wave dampening structure at mangrove sapling replanting coastal area and/or artificial reefs for fish breeding ground.
\end{abstract}

Keywords: Transmission; Dissipation; Reflection; Porous; Submerged

\section{Introduction}

There are many angles in describing what is a breakwater. Among others are, a structure constructed on coasts as part of coastal defense against both wind generated waves and longshore drift, as an offshore barrier to break the force of waves and as an enclosed structure to protect and provide calm waters inside the anchorage or basin area by reflecting and dissipating wave energy. But mostly, especially in nearshore and inshore areas, the breakwater is constructed to protect shoreline from erosion due to wave action. The breakwaters can be a permeable or solid type, either stationed below (a submerged breakwater) or above (emerged, at all time) the water surface depends on its' intended applications. A permeable submerged breakwater, also referred to as artificial 'reefs' is more environmentally friendly and is becoming more preferable as a protection structures [1,2]. expressed the potential of dome-shaped artificial reefs as an environmental enhancer as well as a wave attenuator. The first installation of the submerged reef was in southern Caribbean shore of the Dominican Republic. The reef survived the Hurricane George and Hurricane Mitch (Category 5) shortly after installation and has been effectively stabilizing the beach [3].

Currently, more and more breakwaters in various type of materials have been used as a defense mechanism, either a soft or hard structures, i.e. rocks, geotube, concrete blocks and even in some cases, piles[4]. gives an extensive reviews of breakwater in both submerged and emerged conditions, rigid and flexible geometry, in various types of materials, as in conventional rubble mound, and even a pipelines. Mostly, the alternative types are opted to cater for a short supply of rocks especially the boulders.

Needless to say, an extensive experimental and numerical investigations have been conducted to examine the performance of various submerged or semi-immersed structures in dispersing or dissipating waves. Most semi- or submerged structure are porous or permeable to better depress reflections, transmission waves and reducing wave energy. However, substantial findings on the performance of non-porous piles in transmitting waves could be found as early as in 1950's [5] and further researched in later years [6-11]. The performance results from their laboratory experiments are shown in Table 1. A study between non-porous and porous pile range between 0 to 0.222 percent porosity is also thoroughly investigated by $[6,11]$. Their investigations found that a porous medium could introduced better water circulation in confined water body such that in marina. $[12,13]$ completed an investigation on one-row and two-row porous cylinder under semi-emerged and submerged conditions. In their study, they found that less porous cylinder dissipates lesser wave energy as submergence depth increased. The percentage of wave energy loss increased as the number of row increased, but the reflection effects from the increased row escalated as wave frequency risen, which would likely raise an environmental issue if need to adhered to a specified water quality standard requirement.

Nevertheless, there is still a lot of unclear understanding on the geometrical effect of a cylindrical type structures in dissipating wave 
Page 2 of 8

energy that needs to be tackled by researchers out there. Researchers are still investigating the best way, material and ideal geographical features of a structure that could give optimal performance in reducing wave energy either through laboratory or site test. Hence, this experiment is conducted to investigate the performance of the cylindrical models in dissipating wave energy through various hydraulic parameters.

\section{Experimental Setup and Procedures}

Experiment were performed in a wave flume with dimensions of $18 \mathrm{~m}$ (length) $\times 0.9 \mathrm{~m}$ (width) $\times 0.7 \mathrm{~m}$ (height). The test waves are generated using a programmable piston-type wave maker installed at one end of the tank was controlled using an electronic analog control panel and at the other end of the tank, a L-shaped steel bar served as a wave absorber to diminish undesired reflected waves. The wave flume is provided with see through panels on both sides of flume to facilitate observations and photography. Figure 1 depicts the schematic diagram of the experimental setup.

Models were located almost at the middle of the tank at $10 \mathrm{~m}$ away from the wave maker. Capacitance type wave probes were installed, three on the sea side (upstream) and two at the lee side (downstream) of the cylinder model. The upstream three, numbered \#1, \#2, and \#3, were used to record the incident and reflected waves in front of the models. While probe \#4 and \#5 were installed downstream to record wave transmission over models.
In this study, the quantification of two records are analyzed using the following guideline [12]:

$0.05<\Delta \mathrm{l} / \mathrm{L}<0.45$.

where,

$\Delta \mathrm{l}=$ distance between any two wave gauges; and

$\mathrm{L}=$ incident wave length

Following data analysis, the reflection coefficient, $\mathrm{K}_{\mathrm{r}}$ is expressed by,

$\mathrm{K}_{\mathrm{r}}=\mathrm{H}_{\mathrm{r}} / \mathrm{H}_{\mathrm{i}}$

where,

$\mathrm{H}_{\mathrm{r}}=$ reflected wave height;

$\mathrm{H}_{\mathrm{i}}=$ incident wave height; and

$\mathrm{H}_{\mathrm{t}}=$ transmission wave height

the transmission coefficient can be expressed by,

$\mathrm{K}_{\mathrm{t}}=\mathrm{H}_{\mathrm{t}} / \mathrm{H}_{\mathrm{i}}$

and total energy loss, $\mathrm{E}_{\mathrm{l}}$ is expressed by,

$\mathrm{E}_{\mathrm{l}}=1-\mathrm{K}_{\mathrm{t}}^{2}-\mathrm{K}_{\mathrm{r}}^{2}$.

\begin{tabular}{|l|l|l|l|l|l|l|l|}
\hline No. & Type of breakwater & Water level $\mathbf{( c m})$ & Wave period $(\mathbf{s e c})$ & Wave Parameters & Porosity, $\mathbf{P}$ & Range of $\mathbf{K}_{\mathrm{t}}$ & Reference \\
\hline 1 & Vertical circular cylinders & 45 & nil & $\mathrm{H} / \mathrm{L}=0.046-0.078$ & $0.26-0.52$ & $0.1-0.85$ & {$[5]$} \\
\hline 2 & Vertical thin barriers & $47-70$ & Nil & $\mathrm{H} / \mathrm{L}=0.024-0.082$ & Nil & $0.01-0.95$ & {$[13]$} \\
\hline 3 & Steel pile & 40 & 1.7 & $\mathrm{H}=3.9-18.6$ & $0.05-0.2$ & $0.22-0.7$ & {$[6]$} \\
\hline 4 & Steel pile & $91-116$ & $1.58-2.20$ & $\mathrm{H}=15-27$ & 0.05 & $0.28-0.42$ & {$[7]$} \\
\hline 5 & Circular cylinder & 90 & Nil & $\mathrm{H} / \mathrm{L}=0.025$ & $0.05-0.43$ & $0.28-0.83$ & {$[8]$} \\
\hline 6 & Pile & 30 & Nil & $\mathrm{H} / \mathrm{L}=0.33-0.75$ & $1-4$ & $0.87-0.95$ & {$[9]$} \\
\hline 7 & Pile & 100 & Nil & $\mathrm{H}=6-24$ & 0.67 & $0.42-0.82$ & {$[14]$} \\
\hline 8 & $\begin{array}{l}\text { Two rows perforated hollow } \\
\text { piles }\end{array}$ & 40 and 50 & $1.5-2.25$ & $\mathrm{H}=3-22$ & 0.0625 & $0.7-0.89$ & {$[11]$} \\
\hline
\end{tabular}

Table 1: Various Studies on Cylindrical Structures 
Citation: Awang NA, Anuar NM, Sidek FJ (2018) Potential Multi-Function Cylinder as Wave Attenuator.. J Coast Zone Manag 21: 460. doi:

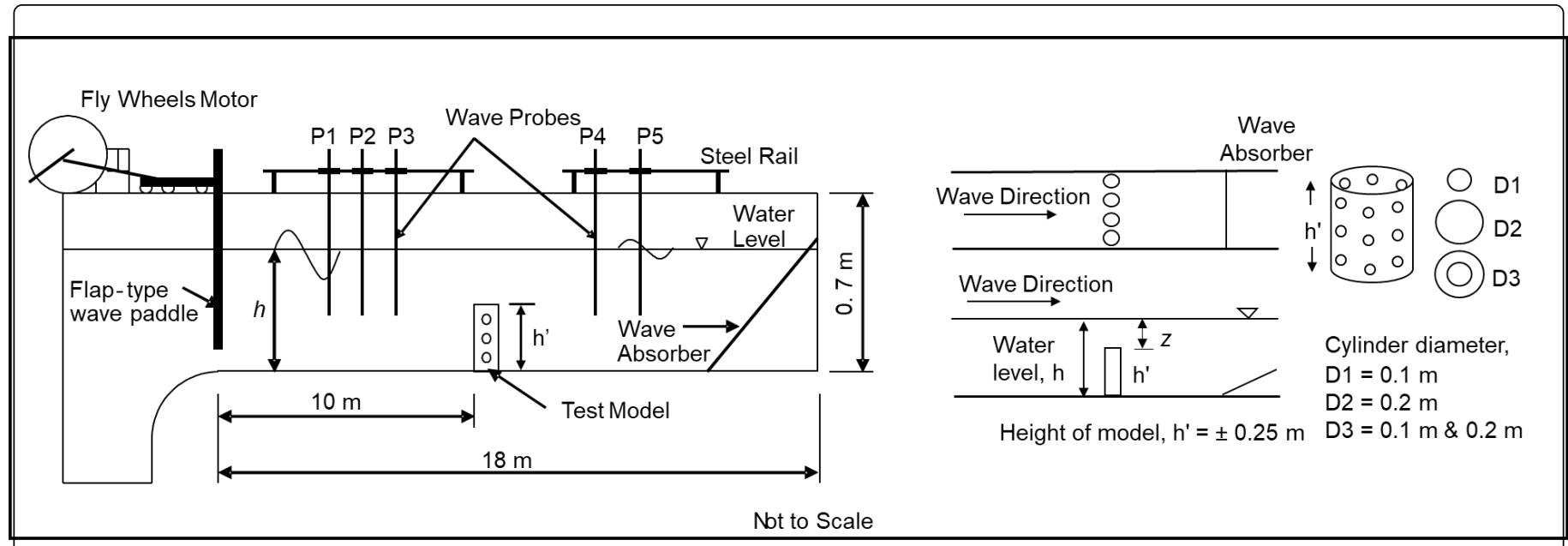

Figure 1: Schematic diagram of Wave Flume and dimension details of the model

\section{The Model}

Figure 2 shows the definition sketch and detail of the cylinder models. Each model unit is constructed from PVC pipe. Four different porous model units were manufactured, representing four different porosities varying from 0.0625 to 0.48 . Porosity, $\mathrm{P}$, is defined as the ratio of pores to the total surface area of the cylinder model. Two sizes of cylinder with diameter, $\mathrm{D}=0.1 \mathrm{~m}$ and $0.2 \mathrm{~m}$ of identical height, $\mathrm{h}^{\prime}=$ $0.25 \mathrm{~m}$ are used to form one-row of four identical model units, for each porosity size of the cylinder model, as shown in Figure 2.

\begin{tabular}{|c|c|c|c|c|c|}
\hline \multirow{2}{*}{ Model } & \multicolumn{5}{|c|}{ Experiment Parameters } \\
\hline & Water level, $\mathrm{h}(\mathrm{m})$ & Relative submergence depth, $z / h$ & Porosity, $\mathrm{P}$ & Wave frequency, $\mathrm{Hz}$ & Wave Period, T (s) \\
\hline $\begin{array}{l}\text { D1 } \\
\text { D2 } \\
\text { D3 }\end{array}$ & $0.27,0.30,0.35$ & $0.074,0.17,0.29$ & $\begin{array}{l}0.0625,0.14,0.28, \\
0.48\end{array}$ & $\begin{array}{l}24,27,30,32,34,36,39 \\
42,45,47\end{array}$ & $\begin{array}{llll}1.67, & 1.49, & 1.34, & 1.25 \\
1.18, & 1.12, & 1.03, & 0.96 \\
0.90, & 0.85\end{array}$ \\
\hline
\end{tabular}

Table 2: summarize the experimental runs for the cylindrical models.

Figure 2: Cylinder model -D1 (top), D2 (middle) and D3 (bottom), left to right - porosity, $\mathrm{P}=0.0625,0.14,0.28$ and 0.48 , respectively. 


\section{The experimental tests}

Each of the models were tested using three water levels, $0.27 \mathrm{~m}, 0.30$ $\mathrm{m}$ and $0.35 \mathrm{~m}$ under uniform wave conditions and various frequencies. Incident wave frequencies were selected from 24 to $47 \mathrm{~Hz}$ for each water level. The $47 \mathrm{~Hz}$ is the peak frequency that can be used at the lowest water level due to the limitations of the flap-type wave paddle to generate waves without breaking before it reaches the tested cylinder. In this study the tested cylinder height was kept constant. Each test started with a quiescent surface and the models were fixed firmly in the flume bed to prevent unwanted vibration or ripples. Table 2 summarize the experimental runs for the cylindrical models.

\section{Results and discussion}

Three models with four different porosities (12 cases) were examined to elucidate the effects of the porosity of submerged models on wave transmissions under various water levels. First, D1, D2, and D3 model in various porosities were tested in different water level conditions and wave steepness, $\mathrm{H}_{\mathrm{i}} / \mathrm{L}$, which resulted in variations of transmission, reflection and energy loss coefficients. Second, the effect of cylinder size or model diameter in breaking the surface wave were tested with respect to wave number, kh.

Figure 3 shows the correlation between wave transmission and reflection coefficients and the variation of $\mathrm{Hi} / \mathrm{L}$ at water level $0.27 \mathrm{~m}$. Three sub-graphs, (a) to (d), show the results of $\mathrm{Kt}$, and $\mathrm{K}_{\mathrm{r}}$ values obtained using model D1, D2, and D3 with porosities of $0.0625,0.14$, 0.28 , and 0.48 , respectively. The $\mathrm{Kt}$, and $\mathrm{Kr}$ values were plotted on the left and right of each sub-graph, respectively. Four symbols in each graphs represent the experimental results obtained using four types of porosities. The graphs indicate the effect of cylinder's perforations on wave reflection and transmission at a given model porosity.

As shown in Figure 3, the geometrical effect of the model becomes apparent as the porosity declines. The decreased in Kt value is more significant in D1 model as compared with model D2 and D3 especially when the porosity is 0.0625 . The $\mathrm{Kt}$ is higher when $\mathrm{Hi} / \mathrm{L}$ is less than 0.013 , since longer incident waves are likely to pass through the model and less energy is dissipated. The value of $\mathrm{K}_{\mathrm{t}}$ is minimum at $\mathrm{Hi} / \mathrm{L}$ between 0.02 to 0.03 . When the porosity increase from 0.0625 to 0.48 , the maximum decrease in $\mathrm{Kt}$ value for model D1 is around 0.14 . While in model D2 and D3, the maximum decrease in $\mathrm{K}_{\mathrm{t}}$ value are 0.28 and 0.31 , respectively. No obvious effects of model's type on $K_{t}$ were observed especially when the porosity is above 0.14. As for wave reflection, $K_{r}$, the effect of porosity in all model tested is insignificant at all $\mathrm{H}_{\mathrm{i}} / \mathrm{L}$ parameter. As shown in the right graph of Figure 3, the experimental results display minimal variance in $\mathrm{K}_{\mathrm{r}}$ value when $\mathrm{H}_{\mathrm{i}} / \mathrm{L}$ is less than 0.013. Almost all the $\mathrm{K}_{\mathrm{r}}$ values are in the range of $0.25-0.55$ at $\mathrm{H}_{\mathrm{i}} / \mathrm{L}=0.006-0.013$ and $\mathrm{K}_{\mathrm{r}}<0.35$ at $\mathrm{H}_{\mathrm{i}} / \mathrm{L}=0.02-0.03$, irrespective of model type. Therefore, Figure 3 elucidates the effect of porosity on wave transmission and reflection. 
Citation: Awang NA, Anuar NM, Sidek FJ (2018) Potential Multi-Function Cylinder as Wave Attenuator.. J Coast Zone Manag 21: 460. doi: $10.4172 / 2473-3350.1000460$

Page 5 of 8
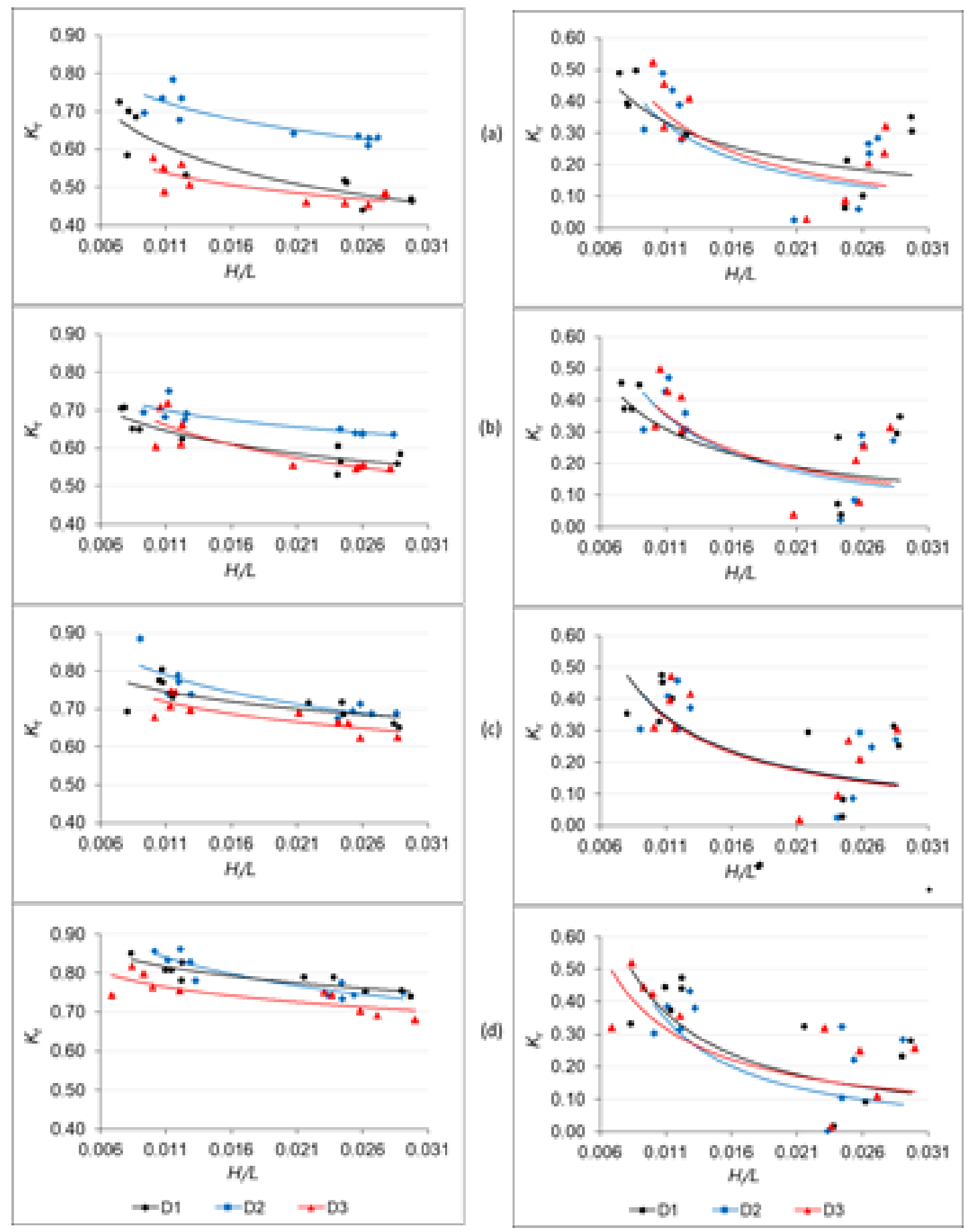

Figure 3: Effect of perforations on $\mathrm{K}_{\mathrm{t}}$ (left) and $\mathrm{K}_{\mathrm{r}}$ (right) for D1, D2 and D3 cylinder at $\mathrm{h}=0.27 \mathrm{~m}$. Sub-graphs (a) to (d) show results for cylinders with porosity, $\mathrm{P}=0.0625,0.14,0.28$ and 0.48 respectively.

Figure 4 shows the results of wave energy loss, El. Four sub-graphs, (a) to (d), present the experimental results of model D1, D2, and D3 for cases of porosities $0.0625,0.14,0.28$, and 0.48 , respectively. The Figure shows that the effect of the type of model is unclear when porosity increased above 0.0625 . The maximum variations of $E_{1}$, for model D1, D2, and D3 is almost similar with $\mathrm{E}_{1}$ do not exceed 0.6 (at porosity 0.28 and 0.48 ) in all $\mathrm{H}_{\mathrm{i}} / \mathrm{L}$. Nonetheless, this phenomenon is different when the porosity is small with all models show a distinct variance in $\mathrm{E}_{\mathrm{l}}$. The effect of smaller porosity is most significant in dual cylinder model D3 as compared with model D1 and D2, with the 
maximum variance in $\mathrm{E}_{1}$ value is lowest at all $\mathrm{H}_{\mathrm{i}} / \mathrm{L}$ values. Higher frequency produced higher wave energy and shorter wave length. Thus, indicated that the dual cylinder setup for model D3 is effective in dissipating more wave energy at higher $\mathrm{H}_{\mathrm{i}} / \mathrm{L}$ values as compared to single cylinder model setup in all porosity tested.

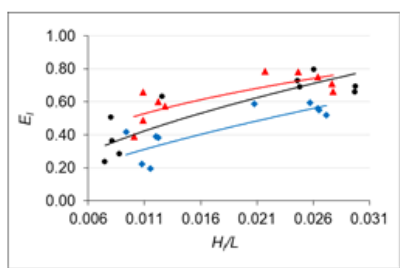

(a)

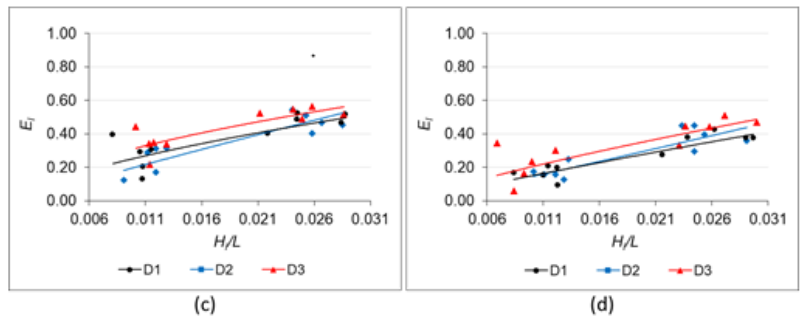

Figure 4: Effect of perforations.

$\mathrm{P}$, on El for D1, D2 and D3 cylinder at $\mathrm{h}=0.27 \mathrm{~m}$. Sub-graphs (a) to (d) show results for cylinders with porosity, $\mathrm{P}=0.0625,0.14,0.28$ and 0.48 respectively. Figure 5 displays the experimental results of $\mathrm{K}_{\mathrm{t}}$ and $\mathrm{K}_{\mathrm{r}}$. three sub-graphs, (a) to (c), present the test results for cases of model D1, D2, and D3 at porosity 0.0625 , respectively. The effect of water level increment on $\mathrm{K}_{\mathrm{t}}$ is more pronounced for model D2 and D3, a bigger diameter cylinder, than smaller diameter cylinder, model D1. In Figure $5 b$ and $6 c, K_{t}$ decreased when water level decreased. From water level, $\mathrm{h}=0.27 \mathrm{~m}$ to $0.30 \mathrm{~m}$, the variance in $\mathrm{K}_{\mathrm{t}}$ for D2 and D3 is almost similar, the increment does not exceed 0.12 for $\mathrm{H}_{\mathrm{i}} / \mathrm{L}$ lower than 0.02. The increased in $K_{t}$ is more than 0.1 for $D 2$ and less than 0.1 for D3 at $\mathrm{H}_{\mathrm{i}} / \mathrm{L}>0.02$, respectively. $\mathrm{K}_{\mathrm{t}}$ grows to more than 0.8 as $\mathrm{H}_{\mathrm{i}} / \mathrm{L}$ approaches 0.011 when $\mathrm{h}=0.35 \mathrm{~m}$, and declines as $\mathrm{H}_{\mathrm{i}} / \mathrm{L}$ approaches 0.022 for model D2. $K_{t}$ remains between $0.66-0.92$ when $H_{i} / L$ is less than 0.02 and decreases below 0.66 when $\mathrm{Hi} / \mathrm{L}$ starts to increase at $\mathrm{h}=$ $0.35 \mathrm{~m}$ for model D3.

At intermediate water level, $\mathrm{h}=0.30 \mathrm{~m}$, as $\mathrm{H}_{\mathrm{i}} / \mathrm{L}$ increases to 0.015 , the $\mathrm{K}_{\mathrm{t}}$ is decreases from 0.79 to 0.72 and further declines as $\mathrm{H}_{\mathrm{i}} / \mathrm{L}$ approaches 0.022 for model D2. As for model D3, when $\mathrm{H}_{\mathrm{i}} / \mathrm{L}$ increase from 0.08 to $0.015, \mathrm{~K}_{\mathrm{t}}$ decreases from 0.69 to 0.58 and further decrease to less than 0.55 as $\mathrm{H}_{\mathrm{i}} / \mathrm{L}$ exceed 0.024 , respectively. $\mathrm{K}_{\mathrm{r}}$ decreases as wave steepness $\mathrm{H}_{\mathrm{i}} / \mathrm{L}$ decreases. The effect of water level increment on $\mathrm{K}_{\mathrm{r}}$ is not that significant, where, at $\mathrm{H}_{\mathrm{i}} / \mathrm{L}$ between 0.007 to 0.035 , the decline trends are similar in both model D2 and D3.

Figure 6 show the primary wave energy loss due to submergence depth of cylinder. The Figure formats are the same as used in Figure 5. For low submergence depth, $\mathrm{z} / \mathrm{h}=0.074$ (water level, $\mathrm{h}=0.27 \mathrm{~m}$ ), the effect of cylinder type is noticeable. $A_{s} \mathrm{H}_{\mathrm{i}} / \mathrm{L}>0.022$, the data show a loss of more than 0.35 of the energy of the incident wave. At higher frequency waves (i.e. the wave steepness $\mathrm{Hi} / \mathrm{L}<0.02$ ), the variations in energy losses due to changes in water level becomes larger as the water level increases. The maximum $\mathrm{E}_{1}$ is about 0.59 at $\mathrm{h}=0.27 \mathrm{~m}$ and 0.30 $\mathrm{m}$, and 0.50 at $0.35 \mathrm{~m}$ water level, in model D1. Whilst in model D2 and D3, at each respective water level, $\mathrm{h}=0.27 \mathrm{~m}, 0.30 \mathrm{~m}$, and $0.35 \mathrm{~m}$, the maximum $\mathrm{E}_{1}$ is about $0.70,0.65$, and 0.43 for $\mathrm{D} 2$; and $0.79,0.70$, and 0.57 , for $\mathrm{D} 3$, respectively. In general, $\mathrm{E}_{1}$ decreases as water level rises, irrespective of cylinder type, but bigger diameter cylinders shown higher energy loss.

Figure 7 plots the effect of model type on wave transmission at different kh. Four sub-graphs, (a) and (b), show the results of tested models with cylinder porosity, 0.0625 and 0.14 at water level, $\mathrm{h}=0.27$ $\mathrm{m}$, and sub-graphs (c) and (d) with cylinder porosity, 0.0625 and 0.14 at water level, $h=0.30 \mathrm{~m}$, respectively. In Figure 7 , all three models show high variance in Kt values at kh between 0.65 to 1.08 , with the changes are more pronounced in model with porosity 0.0625 at water level at $0.27 \mathrm{~m}$. The effect of cylinder type on wave transmission is evident in all kh values irrespective of porosity and water level change, especially between model D1 and D3. The significant variance of $\mathrm{K}_{\mathrm{t}}$ between D1 and D3 model is due to the presence of double cylinder in model D3 which provides high turbulence effect on the model's crest, thus dampened the wave energy, hence, less wave is transmitted. Even though model D1 and D2 are constructed from a single cylinder but differ in diameter, the effect of cylinder geometry on Kt values is unclear especially at kh between 0.65 and 1.08 , but the difference in Kt between the model is significant as $\mathrm{kh}>1.08$ (higher wave frequency or shorter wave length). A longer wave length generated by low frequency waves, hence, lower kh, produced low wave energy and turbulence effect, thus the difference in diameter has likely less significant effect in dampening the wave at the lee of the model. In general, model D3 gives the best performance in attenuating waves with the least waves transmitted especially at higher wave frequency $(\mathrm{kh}>1.08)$ and model D1 is the least effective porous cylinder to attenuate wave energy.

Experimental results have shown that the incident wave conditions and the submerged breakwater geometry influence the wave fields. The porosity of the breakwater also plays an important role in dissipating wave energy. When the measurements were being made, strong turbulence were observed after waves passed bigger diameter cylinder unit, less porous, and low submerged model, indicating that the primary wave energy is thus reduced significantly, as shown in the results presented herein. 

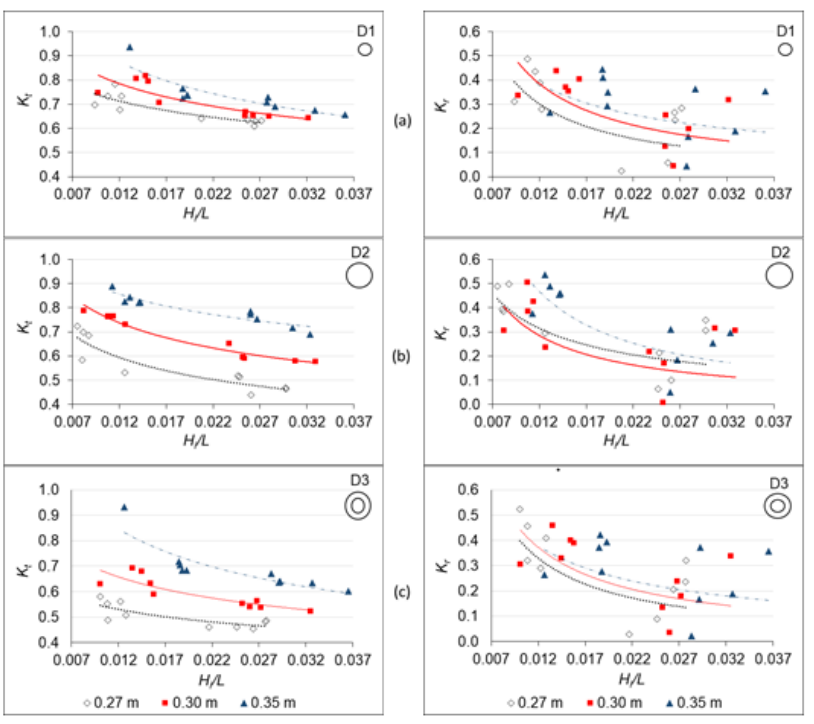

Figure 5: Effect of water level, $\mathrm{h}$, on $\mathrm{Kt}$ and $\mathrm{K}_{\mathrm{r}}$ at cylinder perforation, $P=0.0625$. Sub-graphs (a) to (c) show results for cylinders D1, D2 and D3 respectively.

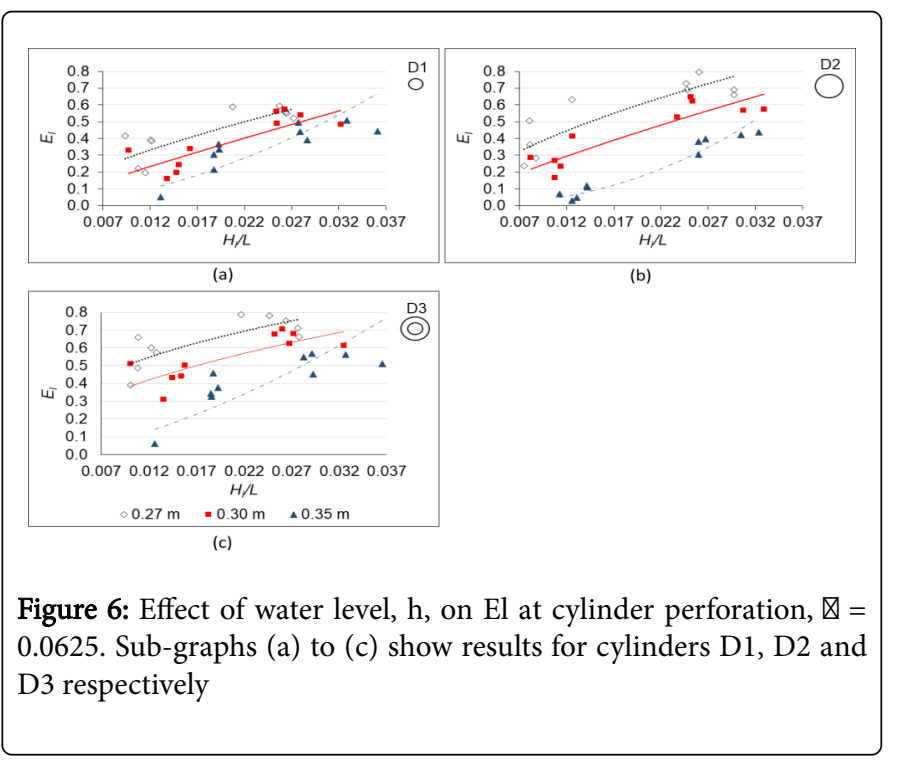

Figure 6: Effect of water level, h, on El at cylinder perforation, $\nabla=$ 0.0625. Sub-graphs (a) to (c) show results for cylinders D1, D2 and D3 respectively
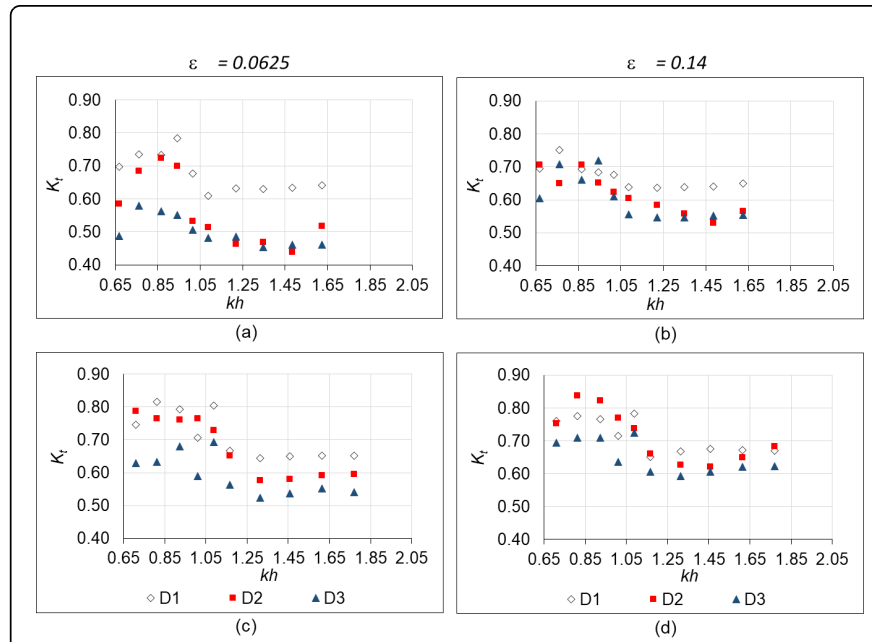

Figure 7: Influence of type of cylinder on $\mathrm{K}_{\mathrm{t}}$ with $\otimes=0.0625$ (left) and 0.14 (right). Sub-graphs (a) to (c) show results for tests under water level, $\mathrm{h}=0.27 \mathrm{~m}$, and $0.30 \mathrm{~m}$ respectively

\section{Conclusion}

This study address how variation of porosity, water level and cylinder type, affect non-breaking wave transformations. The important findings of the laboratory test shown that when the percentage of porosity decreased, more wave energy was dissipated, this resulted in the decrease in transmitted wave heights. It was also found that lower water level $(\mathrm{h}=0.27 \mathrm{~m})$ has a significant influence on the loss coefficient at bigger model size as compared to higher water level at $0.35 \mathrm{~m}$ for similar porosity. Overall, the bigger diameter model (single or double cylinder) with lower porosity $(\mathrm{P}=6.25 \%$ and $14 \%)$ showed promising performance in reducing wave height at the lee of the model, having high percentage of wave energy loss, and smaller model was relatively to be the least effective model in dissipating wave energy against longer waves (that is, lower kh values) to the same environments among all three models. The low reflection and high energy loss showed by all models in shallow water depth and high wave steepness reflects the effectiveness of the cylindrical model to perform as a potential wave barrier for offshore berthing especially in regions where environment friendly is required and tidal fluctuations are large.

\section{References}

1. Black K, Mead S (2000) Submerged structures for coastal protection: A short summary of what they were, why we need them and how they work. ASR LtdHamilton.

2. Armono HD, Hall KR (2003) Wave Transmission on submerged breakwaters made of hollow hemispherical shape artificial reefs. 1st Coastal, Estuary and Offshore Engineering Specialty Conference of the Canadian Society for Civil Engineering.Canada.

3. Harris LE (2009) Artificial reefs for ecosystem restoration and coastal erosion protection with aquaculture and recreational amenities. Reef Journal 1: 235-246.

4. Massie WW (1976) Coastal engineering. Coastal Engineering Group, Delft University of Technology, Delft, Netherland.

5. Costello RD (1952) Damping of water waves by vertical circular cylinders. Trans Am Geophys Union 33: 513-19. 
Citation: Awang NA, Anuar NM, Sidek FJ (2018) Potential Multi-Function Cylinder as Wave Attenuator.. J Coast Zone Manag 21: 460. doi: 10.4172/2473-3350.1000460

Page 8 of 8

6. Hayashi T, Hattori M, Kano T, Shirai M (1966) Hydraulic research on the closely spaced pile breakwaters. Coastal Engineering in Japan 9: 107-117.

7. Nagai S (1966) Research on steel pile breakwaters. Proc. 10th Coastal Eng. Conf. Tokyo.

8. Van Weele J, Herbich JB (1972) Wave reflection and transmission for pile arrays. 13th Coastal Eng. Conf. New York.

9. Khader MHA, Rai SP (1981) Wave attenuation due to closely spaced circular cylinders. International Association for Hydraulic Research XIX Congress. New Delhi, India.

10. Mani JS, Pranesh, MD (1986) Pile breakwater floating barrier interaction. 3rd Indian National Conf. India.

11. Rao NBS, Sathyanarayana VS (1999) Laboratory investigation on wave transmission through two rows of perforated hollow piles. Ocean Eng 26: 675-699.
12. Mohd Anuar N, Jaffar Sidek, F (2010) The use of perforated pile breakwaters to attenuate waves. Malaysian Journal of Civil Engineering. 22: $152-170$.

13. Mohd Anuar N, Jaffar Sidek F (2012) Wave characteristics around perforated piles in a two rows arrangement. Malaysian Journal of Civil Engineering, 24: 48-66.

14. Goda Y, Suzuki Y (1976) Estimation of incident and reflected waves in random wave experiments. 15th Coastal Eng. Conf. Haiwaii.

15. Wiegel RL (1960) Transmission of waves past a rigid vertical thin barrier. Journal of Waterways and Harbour Division ASCE 86: 1-12.

16. Grune J, Kohlhase J (1974) Wave transmission through vertical slotted walls. 14th Coastal Eng Conf. New York. 